\title{
Association of body mass index with serum 25 hydroxy Vitamin D status in healthy pre and postmenopausal females
}

\author{
Jyoti Batra ${ }^{1}$, Sudeep Kumar ${ }^{2 *}$, Manisha Arora ${ }^{3}$, Sumesh Prasad Sah ${ }^{4}$, Roshan Kumar Mahat \\ ${ }^{1}$ Professor \& Associate Dean, ${ }^{2}$ Assistant Professor, ${ }^{3}$ Professor \& Head, ${ }^{4,5}$ Demonstrator, ${ }^{1}$ Dept. of Biochemistry, Santosh \\ University, Ghaziabad, Uttar Pradesh, ${ }^{2-5}$ Dept. of Biochemistry, Muzaffarnagar Medical College, Muzaffarnagar, Uttar Pradesh, \\ India
}

*Corresponding Author:

Email: sudeepty@gmail.com

\begin{abstract}
Introduction: BMI is associated with Vitamin D in pre and postmenopausal women. As the estrogen level decreases during menopause, this promotes hypovitaminosis D. The present study assessed Vitamin D status and found its correlation with BMI in healthy pre- and postmenopausal women.

Materials and Methods: This cross-sectional study was conducted on 100 pre-menopausal and 100 postmenopausal women. Blood samples were collected for estimation of Vitamin D by fully automated Chemi Luminescent Immuno Assay. Statistical analyses were done by using Graphpad Prism 6 and Pearson correlation coefficient was computed between Vitamin D and BMI. Results: The mean levels of weight and BMI were increased significantly in post-menopausal women as compared to premenopausal women and the mean level of Vitamin D was decreased significantly in postmenopausal women as compared to premenopausal. In the present study, we observed that the BMI is significantly and negatively correlated with Vitamin D concentration in both pre $(\mathrm{r}=-0.549)$ and postmenopausal $(\mathrm{r}=-0.736)$ women and it was statistically significant.

Conclusion: Vitamin D deficiency is prevalent in pre- and postmenopausal with BMI greater than $25 \mathrm{~kg} / \mathrm{meter}^{2}$ and the decrease in Vitamin D was more in postmenopausal women as compared to premenopausal women and the Vitamin D was negatively associated with BMI in both pre and postmenopausal women.
\end{abstract}

Keywords: Postmenopausal, BMI, Vitamin D, Estrogen, Osteoporosis.

\section{Introduction}

Age-related decline of Vitamin D reserves, low exposure to sunlight and low intake of Vitamin D are major factors contributing to hypovitaminosis D. Vitamin D plays an important role in bone growth and maintenance by enhancing intestinal absorption of calcium and influencing bone metabolism in other ways. In the mid-to-late 20th century, it became evident that Vitamin D inadequacy was very common among the elderly and was implicated in the development of osteopenia and osteoporosis..$^{1-3}$

Vitamin D status is highly different between various countries. ${ }^{4,5}$ This is caused by different exposure to sun light, dietary intake of Vitamin D and the use of supplements. The prevalence of hypovitaminosis $\mathrm{D}$ has been reported to be greater than $35 \%$ in such high-risk populations. Even in independent-living elderly populations, the prevalence has been reported to be $6-16 \% .{ }^{6,7}$

The majority of studies reported a high prevalence of serum $25(\mathrm{OH})$ D values below specified cut-off points among healthy post-menopausal women.

Vitamin D deficiency or insufficiency prevails in all over the Indian subcontinent with prevalence ranging from $70 \%$ to $100 \% .{ }^{8}$ Vitamin D deficiency is the most under-diagnosed and undertreated global problem affecting majority of individuals irrespective of their age gender, race, and geography. ${ }^{9}$ Vitamin D is photosynthesized in the skin form 7-dehydrocholesterol on exposure to sunlight ultraviolet (B) rays. Proper amount of sun exposure is ought to suffice for the prevention of Vitamin D deficiency. In spite of this fact and plentiful of sunlight in countries such as India, it is seen that large population of adolescents has low or borderline low serum 25-hydroxyVitamin $(25[\mathrm{OH}] \mathrm{D})$ level. Dietary pattern, fortification of food, limited sun exposure, use of sunscreen, pigmentation of skin, and social taboos facilitate the Vitamin D deficiency in India.

In addition to bone and calcium metabolism, Vitamin D may be having several health protective effects against Type 1 diabetes mellitus, cardiometabolic risk such as hypertension, obesity, and cancer. $^{10}$

Recent studies in adult population suggested that adequate 25(OH) D levels could be associated with increased insulin sensitivity index and consequently weight loss. ${ }^{11}$ In one of the previous studies, whole body irradiation produces increased in 25(OH)D level in obese individuals (body mass index [BMI]>30 $\mathrm{kg} / \mathrm{m} 2$ ] that was $57 \%$ lower as compared to normal weight individual (BMI $<25 \mathrm{~kg} / \mathrm{m} 2)$. Several mechanism have been proposed to explain low $25(\mathrm{OH}) \mathrm{D}$ levels in obese adults, one of it is sequestration of Vitamin D by adipose tissue. ${ }^{12}$

\section{Materials and Method}

This cross-sectional study was carried out in the Department of Biochemistry, Santosh Medical College Ghaziabad in collaboration with Department of 
Biochemistry Muzaffarnagar Medical College, Muzaffarnagar. Two hundred apparently healthy women out of which 100 were healthy pre-menopausal and 100 were postmenopausal women attending Obstetrics and Gynaecology out Patient Department of Muzaffarnagar Medical College and Hospital, Muzaffarnagar. Ethical clearance was obtained from the Institutional Ethical Committee and written informed consent was obtained from study subjects. Healthy female of 30-60 years of age (without any acute/chronic illness) were included in the present study. The female subjects, on Vitamin D or calcium supplementations, on drug for obesity or doing severe exercise for weight reduction were excluded from this study.

Anthropometric Measurements: Subjects were weighed with light clothing, to the nearest $0.1 \mathrm{~kg}$ and height measured (to the nearest $0.1 \mathrm{~cm}$ ) using a stadiometer (RGZ-120).
Body Mass Index (BMI) was calculated by using standard formula. ${ }^{13}$

BMI=Weight $(\mathrm{Kg}) /$ Height $(\mathrm{m}){ }^{2}$

Biochemical Parameters: Venous blood $(3 \mathrm{ml})$ was drawn from all participants, serum was separated for analyzing 25(OH)D levels. The most common and sensitive index for assessing Vitamin $\mathrm{D}$ status is $25(\mathrm{OH}) \mathrm{D}$. The serum concentration of $25(\mathrm{OH}) \mathrm{D}$ was measured by fully automated Chemi Luminescent Immuno Assay. ${ }^{14}$

Statistical Analysis: All data were expressed as the mean \pm standard deviation (SD) and unpaired Student's $\mathrm{t}$ - test was used to compare mean $\pm \mathrm{SD}$ between the groups. Pearson correlation coefficient was computed between Vitamin D and BMI. A p-value less than 0.05 considered as statistically significant.

Table 1: Distribution of study subjects according to Age

\begin{tabular}{|c|c|c|c|}
\hline S. No. & Age (Years) & Pre-Menopausal & Post-Menopausal \\
\hline 1 & $30-40$ & 64 & - \\
\hline 2 & $40-50$ & 36 & 34 \\
\hline 3 & $50-60$ & - & 66 \\
\hline & Total & 100 & 100 \\
\hline
\end{tabular}

Table:-2 Anthropometric and biochemical parameters in study subjects

\begin{tabular}{|c|l|c|c|c|}
\hline S. No & \multicolumn{1}{|c|}{ Parameters } & $\begin{array}{c}\text { Pre-Menopausal } \\
(\text { mean } \pm \text { SD) }\end{array}$ & $\begin{array}{c}\text { Post-Menopausal } \\
(\text { mean } \pm \text { SD) }\end{array}$ & P-Value \\
\hline 1 & Weight $(\mathrm{Kg})$ & $62.80 \pm 6.29$ & $67.16 \pm 8.11$ & $<0.001$ \\
\hline 2 & Height $(\mathrm{Meter})$ & $1.58 \pm 0.052$ & $1.59 \pm 0.58$ & 0.7 \\
\hline 3 & BMI $\left(\mathrm{Kg} / \mathrm{m}^{2}\right)$ & $24.92 \pm 2.65$ & $26.55 \pm 3.15$ & $<0.001$ \\
\hline 4 & Vitamin-D $(\mathrm{ng} / \mathrm{ml})$ & $21.67 \pm 5.03$ & $19.40 \pm 5.33$ & 0.002 \\
\hline
\end{tabular}

Table 3: Vitamin D status in pre and post-menopausal women according to BMI

\begin{tabular}{|c|c|c|c|c|}
\hline S. No. & Particulars & BMI $\left(\mathbf{K g} / \mathbf{m}^{2}\right)$ & $\mathbf{N}$ & Mean Vit-D $(\mathbf{n g} / \mathbf{m l})$ \\
\hline \multirow{2}{*}{1} & Premenopausal & $<25 \mathrm{Kg} / \mathrm{m}^{2}$ & 64 & 24.02 \\
\cline { 3 - 5 } & $(100)$ & $>25 \mathrm{Kg} / \mathrm{m}^{2}$ & 36 & 17.50 \\
\hline \multirow{2}{*}{2} & Postmenopausal & $<25 \mathrm{Kg} / \mathrm{m}^{2}$ & 34 & 23.12 \\
\cline { 3 - 5 } & $(100)$ & $>25 \mathrm{Kg} / \mathrm{m}^{2}$ & 66 & 16.05 \\
\hline
\end{tabular}

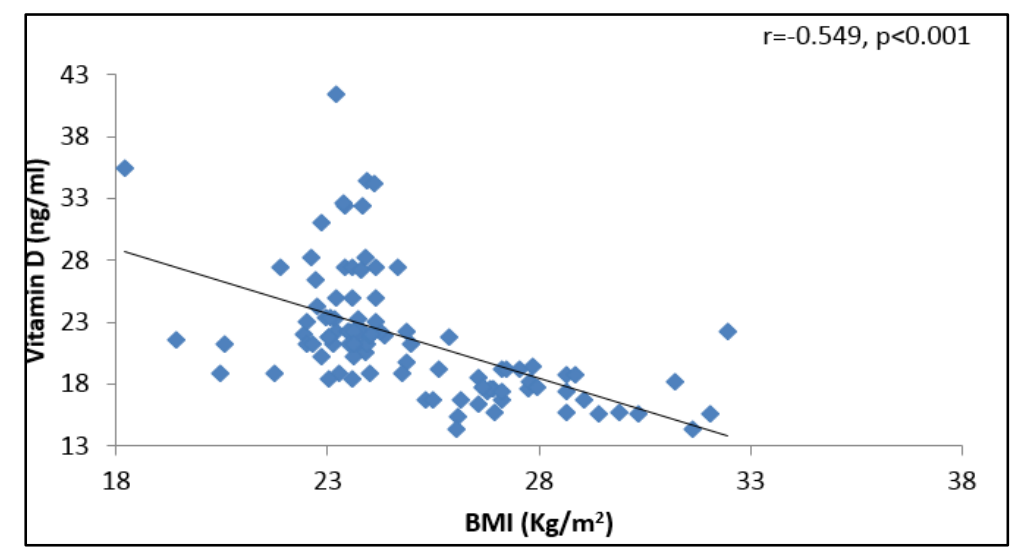

Fig. 1: Pearson's correlation between Vitamin D and BMI in premenopausal women 


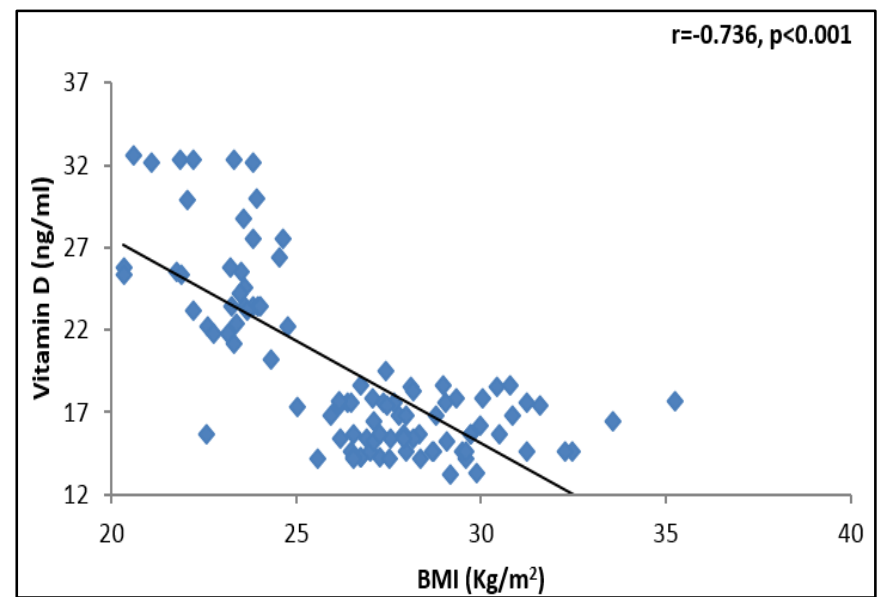

Fig. 2: Pearson's correlation between Vitamin D and BMI in post-menopausal women

\section{Discussion}

The hormonal alterations in women in the premenopausal and postmenopausal periods may result in musculoskeletal, metabolic, and cardiovascular conditions, and may affect mental health. All these conditions may also be related to Vitamin D deficiency. Also women in the premenopausal and postmenopausal period are more susceptible to Vitamin D deficiency and its possible health consequences. It is plausible that in premenopausal and postmenopausal women, estrogen deficiency together with Vitamin D deficiency results in increased risk of metabolic and cardiovascular complications. ${ }^{15}$

In the present study significant decreased levels of Vitamin D was found in postmenopausal women that may be due to the decreased levels of estrogen and progesterone, as compared to premenopausal women. Also the $34 \%$ premenopausal women having BMI greater than 25 and $66 \%$ women having BMI less than 25 . The premenopausal women with BMI greater than $25 \mathrm{~kg} / \mathrm{m} 2$ have low Vitamin-D levels as compared to the premenopausal women having BMI less than 25 .

In case of post-menopausal women, $66 \%$ women were with BMI greater than 25 and $34 \%$ women were with BMI less than 25. The decreased level of Vitamin $\mathrm{D}$ was found in postmenopausal with BMI greater than 25 as compared to postmenopausal women with BMI less than. ${ }^{25}$

During menopause the levels of estrogen and progesterone is decreased. ${ }^{16}$ The activity of enzyme 1$\alpha$-hydroxylase is regulated by estrogen which is responsible for the Vitamin $\mathrm{D}$ activation and upregulation of Vitamin D receptor ${ }^{17}$ There is a gradual decrease in estrogen level produced by the ovaries during menopause. ${ }^{18}$ and this decline in estrogen production may be associated with Vitamin D deficiency.

Menopause is associated with weight gain and changes in body fat distribution, with visceral fat accumulation (central adiposity). The typical gynoid distribution of body fat of premenopausal women gradually turns into the android type distribution characterized by fat accumulation in the abdomen. ${ }^{15}$ In this study, more than $50 \%$ of women working in nonmanual jobs were overweight or obese, and both BMI and the percentage of body fat did not differ significantly between the three groups studied. However, an increased waist-hip ratio (WHR) was more common in early premenopausal and postmenopausal women compared with late premenopausal women.

Previous studies have shown that obesity may be associated with lower serum Vitamin D levels, although the underlying mechanism is not clear. ${ }^{19,20}$ One of the possible explanations could be reduced bioavailability of Vitamin D due to sequestration in excess adipose tissue. ${ }^{15}$ However, Andreozzi et al. ${ }^{21}$ concluded that Vitamin D fat sequestration applied only to individuals with very large amounts of adipose tissue and also showed a negative correlation between serum Vitamin D levels and waist circumference, as well as the android fat to gynoid fat $(\mathrm{A} / \mathrm{G})$ ratio, but not with BMI. The authors suggested that the android disposition of body fat is more closely associated with the onset of metabolic syndrome.

Pearson's Correlation between the different parameters was applied and found a significant negative correlation with BMI in pre (Fig. $1 \mathrm{r}=-0.549$ ) and postmenopausal women (Fig. $2 \mathrm{r}=-0.736$ ) are in agreement with many previous study. ${ }^{22-24}$ The accumulation of visceral fat results in an increased risk of metabolic and cardiovascular complications. ${ }^{25}$ Arunabh et al. ${ }^{26}$ studied a group of women between 20 80 years old and showed that serum Vitamin D levels decreased with an increase in the amount of adipose tissue. Recent studies have shown that Vitamin D may play an active role within the adipose tissue by modulating inflammation, adipogenesis, and adipocyte secretion. ${ }^{27}$ Chacko et al. $^{28}$ in a study of postmenopausal women, showed a negative association between serum Vitamin D levels and BMI, as well as waist circumference. 
The decreased serum Vitamin D levels found in the premenopausal and postmenopausal women in this study may also be attributed to the dietary Vitamin D intake, the extent of the sun exposure, Vitamin D supplementation, and lifestyle. However, some other factors could also influence serum Vitamin D levels. There is lack of clear evidence that Vitamin D supplementation benefits weight loss. Women over 50 years old should be on a calcium- and Vitamin D-rich diet, which might help to prevent osteoporosis. It is also important to remember that calcium and

Vitamin D supplementation are needed during weight reduction, since a restricted diet is associated with decreased estrogen levels and calcium absorption, which may lead to bone loss. ${ }^{15}$

Further studies are needed to establish the optimal dosage of calcium and Vitamin $\mathrm{D}$ the duration of the treatment, and the effect of increasing serum Vitamin D concentration in premenopausal and postmenopausal women working in non-manual jobs, especially those with dyslipidemia and obesity. Diagnosing Vitamin D deficiency and applying supplementation appear to be important steps in the prevention of metabolic and cardiovascular complications.

\section{Conclusions}

In the present study, women with BMI greater than 25 having lower Vitamin D levels as compared to pre and postmenopausal women with BMI less than 25 $\mathrm{kg} / \mathrm{m}^{2}$ i.e the BMI significant and negatively correlated with serum Vitamin D concentration. The decrease in Vitamin D concentration was more in postmenopausal women as compared to premenopausal women. Therefore, increased awareness of the benefits of a Vitamin D-rich diet and Vitamin D supplementation, as well as outdoor physical activity, should be promoted among premenopausal and postmenopausal women to help prevent obesity and unfavorable changes in lipid profile in this population.

\section{References}

1. Lips P. Suboptimal vitamin D status: a risk factor for osteoporosis?. Adv Nutr Res. 1994;9:151-66.

2. Aaron JE, Gallagher JC, Anderson J, Stasiak L, Longton EB, Nordin BE, et al. Frequency of osteomalacia and osteoporosis in fractures of the proximal femur. Lancet. 1974;1:229-33.

3. Exton-Smith AN, Hodkinson HM, Stanton BR. Nutrition and metabolic bone disease in old age. Lancet. 1966;2:999-1001.

4. McKenna MJ. Differences in vitamin D status between countries in young adults and the elderly. Am J Med. 1992;93:69-77.

5. Lips P, Duong T, Oleksik A, Black D, Cummings S, Cox $\mathrm{D}$, et al. A global study of vitamin D status and parathyroid function in postmenopausal women with osteoporosis: baseline data from the multiple outcomes of raloxifene evaluation clinical trial. J Clin Endocrinol Metab. 2001;86:1212-21.
6. Omdahl JL, Garry PJ, Hunsaker LA, Hunt WC, Goodwin JS. Nutritional status in a healthy elderly population: vitamin D. Am J Clin Nutr. 1982;36:1225-33.

7. Burnand B, Sloutskis D, Gianoli F, Cornuz J, Rickenbach M, Paccaud F, et al. Serum 25-hydroxyvitamin D: distribution and determinants in the Swiss population. Am J Clin Nutr. 1992;56:537-42.

8. Ritu G, Gupta A. Vitamin D deficiency in India: Prevalence, causalities and interventions. Nutrients. 2014;6:729-75.

9. Van Schoor NM, Lips P. Worldwide vitamin D status. Best Pract Res Clin Endocrinol Metab. 2011;25:671-80.

10. Wang TJ, Pencina MJ, Booth SL, Jacques PF, Ingelsson $\mathrm{E}$, Lanier K, et al. Vitamin D deficiency and risk of cardiovascular disease. Circulation. 2008;117:503-11.

11. Belenchia AM, Tosh AK, Hillman LS, Peterson CA. Correcting vitamin D insufficiency improves insulin sensitivity in obese adolescents: A randomized controlled trial. Am J Clin Nutr. 2013;97:774-81.

12. Yan Y, Hou D, Liang Y, Zhao X, Hu Y, Liu J, et al. Tracking body mass index from childhood to adulthood for subclinical cardiovascular diseases at adulthood. $J \mathrm{Am}$ Coll Cardiol 2016;67:1006-7.

13. http://www.nhs.uk/Tools/Pages/Healthyweightcalculator. aspx

14. Valcoura A, Zieroldb C, Angela L, Podgorskib, Gregory $\mathrm{T}$, Olsonb, John V, et al. A novel, fully-automated, chemiluminescent assay for the detection of 1,25dihydroxyvitamin D in biological samples. J Ster Biochem Mole Bio. 2016;164:120-26.

15. Lerchbaum E. Vitamin D and menopause - a narrative review. Maturitas. 2014;79:3-7.

16. Nelson HD. Menopause. The Lancet 2008;371:760-70.

17. Kanwar G, Sharma N, Shekhawat M, Sharma P, Hada R, Chandel CS. Comparison of Vitamin D Levels in Pre And PostMenopausal Type 2 Diabetic Females. IOSR-JDMS. 2015;14:70-73.

18. Harlow SD, Gass M, Hall JE, Lobo R, Maki P, Rebar $\mathrm{RW}$, et al. Executive summary of the Stages of Reproductive Aging Workshop + 10: addressing the unfinished agenda of staging reproductive aging. Menopause. 2012;19:87-95.

19. Pelczyńska M, Grzelak T, Walczak M, Czyżewska K. hypovitaminosis D and adipose tissue - cause and effect relationships in obesity. Ann Agric Environ Med. 2016;23:403-9.

20. Wojcik M, Janus D, Kalicka-Kasperczyk A, Sztefko K, Starzyk JB. The potential impact of the hypovitaminosis D on metabolic complications in obese adolescents Preliminary results. Ann Agric Environ Med. 2017;24:636-39.

21. Andreozzi P, Verrusio W, Viscogliosi G, Summa ML, Gueli N, Caaciafesta M, et al. Relationship between vitamin D and body fat distribution evaluated by DXA in postmenopausal women. Nutrition. 2016;32:687-92.

22. Gandhe MB, Velu VK, Shyamini SRS, Saha S, Ramesh $\mathrm{R}$, Babu MS. Circulating 25-hydroxyvitamin D status in apparently healthy adolescents and its association with body mass index in Puducherry population. Ind J Child Health. 2016;3:110-15.

23. Agarwal N, Mithal A, Kaur P, Dhingra V, Godbole MM, Shukla M. Vitamin D and insulin resistance in postmenopausal Indian women. Indian J Endocr Metab. 2014;18:89-93.

24. Al-Agha AE, Shaikhoon SM, Sultan MA, Alsheikh HS. Weight and Body Mass Index in Relation to Vitamin D Status in Healthy 4-13 Years Old Children in Saudi Arabia. RRJMHS. 2016;5:20-24. 
25. Wehr E, Pilz S, Boehm BO, Marz W, Pietsch BO. The lipid accumulation product is associated with increased mortality in normal weight postmenopausal women. Obesity (Silver Spring) 2011;19:1873-80

26. Arunabh S, Pollack S, Yeh J, Aloia JF. Body fat content and 25-hydroxyvitamin D levels in healthy women. $J$ Clin Endocrinol Metab. 2003;88:157-61
27. Mutt SJ, Hyppönen E, Saarnio J, Jarvelin MR, Herzig KH. Vitamin D and adipose tissue-more than storage. Front Physiol. 2014;24:228-29.

28. Chacko SA, Song Y, Manson JE, Horn LV, Eaton C, Martin LW, et al. Serum 25-hydroxyvitamin D concentrations in relation to cardiometabolic risk factors and metabolic syndrome in postmenopausal women. Am J Clin Nutr. 2011;94:209-17. 